\title{
Black Pad Metallography in Electronics
}

\author{
P. Snugovsky \\ Celestica, 844 Don Mills Road, Toronto, Ontario, Canada, M3C 1V7
}

In the last three years solderability defect called Black Pad has gained enclosing attention. "Black Pad" forms during electroless $\mathrm{Ni} /$ immersion $\mathrm{Au}$ (ENIG) plating on printed circuit wiring board (PWB) copper interconnects, but manifests itself at the board assembly stage as a premature, brittle, interfacial solder joint failure. Black Pad cannot be detected by visual inspection before assembly, and it causes catastrophic failures in assembled electronic devices $[1,2]$. The purpose of the study was to employ metallography to reveal the Black Pad defect on bare boards, examine the intermetallic structure formation during soldering on defective pads, and determine the failure mechanism.

The following methods and techniques were used: cross-sections with a protective coating; optical and field emission scanning electron microscopy (SEM, Hitachi model S-4500); energy dispersive X-ray (EDX, Oxford) spectroscopy; and X-ray photoelectron spectroscopy (XPS, PHI 5600 ESCA). The intermetallics were formed using $\mathrm{Sn}-\mathrm{Pb}$ and $\mathrm{Sn}-\mathrm{Ag}-\mathrm{Cu}$ Lead-Free solders on ENIG substrates.

The cross-sectional structure of "normal" interconnects is shown in Fig. 1 a. The pads have a uniform thin gold layer over a nickel layer. Defective ENIG pads in this case created by an anomalous plating process have thick immersion Au on highly corroded electroless Ni (Fig. 1 b). These pads have narrow openings or fissures in the Ni layer, with gold penetration along them. EDX analyses on cross-sectioned pads and XPS depth-resolved analyses showed that the thick $\mathrm{Au}$ layer contained $\mathrm{Ni}, \mathrm{P}$, and $\mathrm{Cu}$. $\mathrm{Au}$ followed the $\mathrm{Ni}$ nodules and layers boundaries, revealing the existing Ni structure, and multi layered $\mathrm{Ni} / \mathrm{Au}$ structure forms. A mechanism for the defective ENIG plating was proposed.

Upon solder reflow, interconnects affected by Black Pad were wetted and solder joints which appear normal formed. Failure occurred after reflow, resulting in open joints. The pad surfaces not only contained $\mathrm{Ni}$ and P, but Sn as well. The detection of Sn with EDX indicated that an intermetallic was formed. High resolution SEM analysis showed that the structure of the intermetallic was flat and brittle.

Investigation of intermetallic formation showed that the pads with defective ENIG coating performed differently during reflow compared to non-defective pads. On problem-free pads with thin $\mathrm{Au}$, the $\mathrm{Me}_{3} \mathrm{Sn}_{4}$ $(\mathrm{Me}=\mathrm{Ni}, \mathrm{Cu}, \mathrm{Au})$ intermetallic crystals originated at the Ni/molten solder interface and grew into solder (Fig. 2 a). $\mathrm{Me}_{3} \mathrm{Sn}$ intermetallic and $\mathrm{Ni}_{3} \mathrm{P}$ compound were formed inside the defective layer. In extreme cases, with highly corroded $\mathrm{Ni}$, the intermetallic-solder interface was flat with no growth into the liquid solder (Fig. 2 b). Intermediate defective $\mathrm{Ni}$ formed two layers: $\mathrm{Me}_{3} \mathrm{Sn}+\mathrm{Ni}_{3} \mathrm{P}$ inside the corroded top layer of the $\mathrm{Ni}$ and $\mathrm{Me}_{3} \mathrm{Sn}_{4}$ growing into the liquid solder. The weakness of the solder joints arose from growth of brittle $\mathrm{Me}_{3} \mathrm{Sn}$ intermetallic layer inside the $\mathrm{Ni}$ and mismatch between the two intermetallics, leading to poor adhesion.

Metallographic characterization of the aged samples detected intermetallic growth and transformation, which improve solder joint strength [3]. 


\section{References}

[1] B. Houghton et al., IPC EXPO. 2 (1999) S18-41.

[2] P. Snugovsky, et al., J. Electrinic Materials. 9 (2001) 1262.

[3] The participation M. Romansky and assistance of Z. Bagheri Lorenza Lombardi, and B. Houghton of Celestica is gratefully acknowledged.

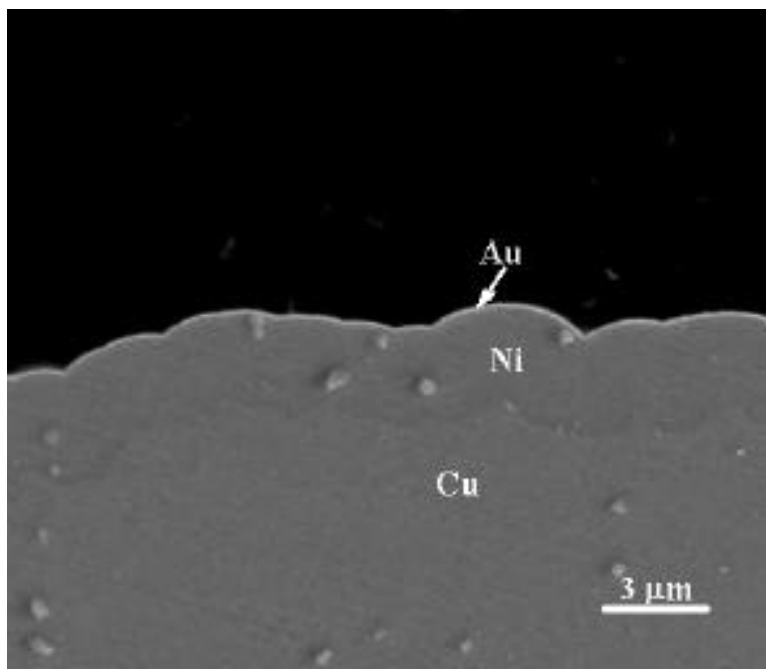

a

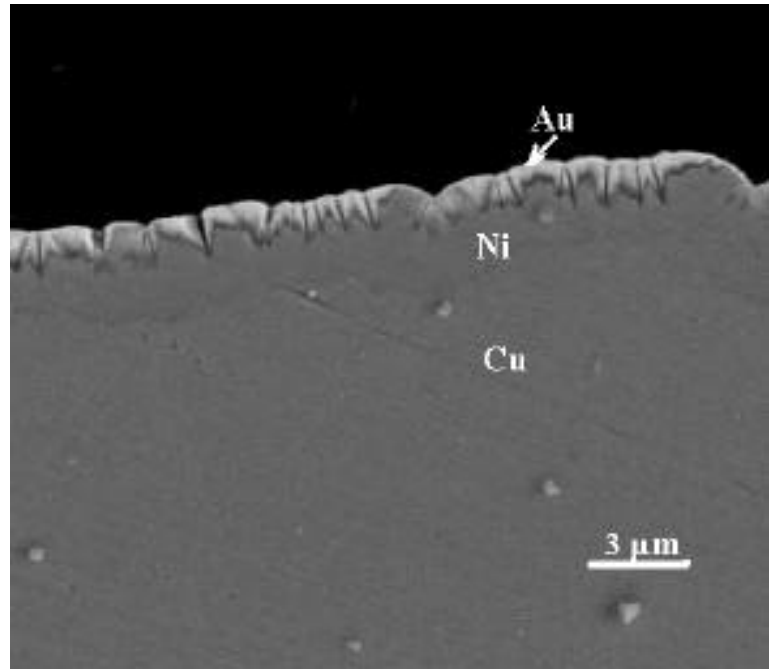

b

FIG. 1. SEM micrographs showing electroless Ni / immersion Au normal interconnect structure (a) and Black Pad structure (b)

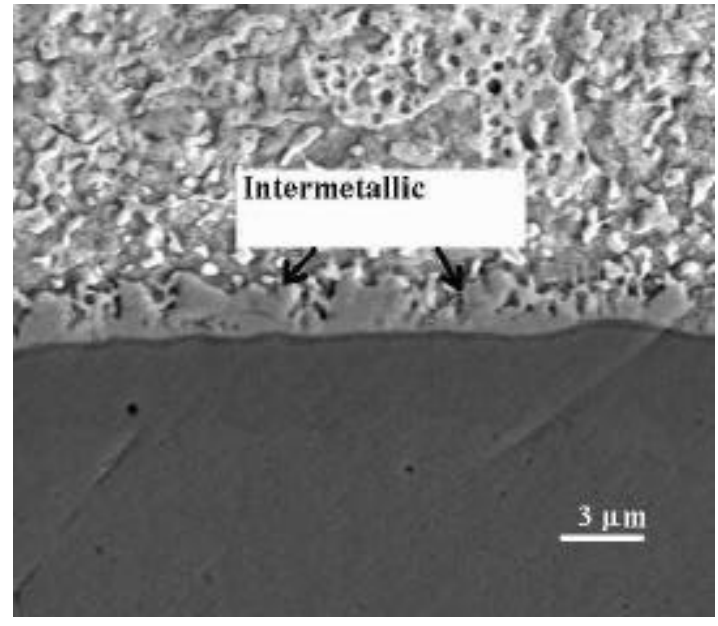

a

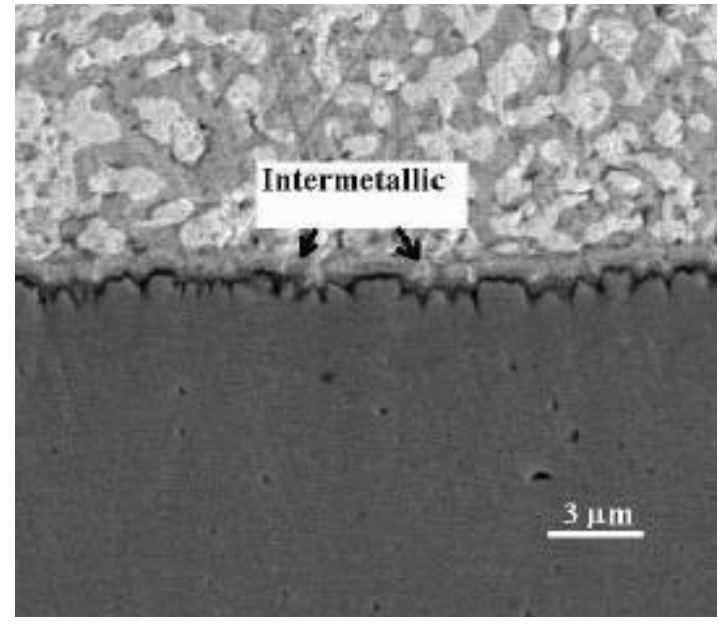

b

FIG. 2. SEM micrographs showing the differences between intermetallics on pads with normal electroless $\mathrm{Ni} /$ immersion Au structure (a) and highly corroded Black Pad structure (b). 